\title{
TEACHING AND RESEARCHING ENGLISH FOR SPECIFIC PURPOSES
}

Elżbieta D. Lesiak-Bielawska

Krakow: Księgarnia Akademicka, 2018

\author{
M. ${ }^{a}$ ÁNGELES ESCOBAR-ÁLVAREZ \\ Universidad Nacional de Educación a Distancia (UNED) \\ maescobar@flog.uned.es
}

The book under review attempts to provide the reader with an overview of new historical research that has been done in recent decades on the practice of teaching English for specific purposes (ESP) both in Europe, with special reference to Poland, and around the world. It also discusses good research practice in Language for specific purposes (LSP), since the author considers many areas of learning experience within the scope of both LSP and ESP such as approach practices, teaching competence, content and language syllabus, materials and curriculum, needs analysis, assessment and evaluation, along with technology implementation. In this sense, the line of the book's inquiry features a wide array of topics existing within the area of ESP pedagogy.

Instruction in ESP is argued to have made significant headway since it has incorporated many instructional processes encompassing needs and language analysis, teaching materials and research methods the same as those found in general language teacher education. The author highlights the demanding skills expected from ESP teachers who need to learn to advance their careers and test new tactics and strategies in their daily practice. Therefore, this book can raise awareness among ESP or LSP instructors and practitioners about the importance of keeping updated, since ESP reading can help them gain a deeper knowledge of their own field of investigation. The same is argued to hold for LSP. However, one may argue that in comparison to general language teacher education, LSP teacher education has received much less attention (Nazari 2020). 


\section{Reviews}

Chapter 1 explains how ESP teaching has evolved in different stages and how countries have been incorporating different approaches over the last four decades. In particular, the chapter discusses the impact of ESP teaching in Western, Central and Eastern Europe, with a focus on Poland's educational context. The topic of ESP methodology is also well addressed based on recent developments in the United States, Asia and Australia. In all these countries, ESP has been gaining ground over the more traditional teaching of General-Purpose English (GPE). Moreover, ESP courses are argued to provide a solution to global mobility for adult learners who need to learn English for their professions although in many cases they are only beginners in their study of the English language.

Following one of the main claims discussed in Chapter 1 , a major obstacle to using authentic and communicative materials lies in learners' low level of English language skills. The study of isolated lexico-grammatical items common in the 1960s could also hinder learners from focusing on the target situation through a rigorous analysis of its linguistic features in terms of its communicative purpose. This issue led to the 'needs-analysis' approach that was firmly established in the 1970s. The main reason for the development of effective communicative approaches was to acquire a desirable communicative competence that could be extended to specific professional or academic settings. Clearly, the use of different genres in the classroom could also favor the acquisition of specialized ESP discourses as part of students' professional training. By highlighting the so-called Content-Based Teaching developed in Canada and the USA in those years and later, the chapter also reinforces the importance of learning professional or academic content through an additional or second language. This was indeed the reason for the dual program of language and content in the European context which resulted in the Content and Language Integrated Learning Approach (CLIL) in the 1990s. Rather than focusing on grammar, the term content referred to the use of subject matter - topics based on student interests or needs - as a vehicle for second/foreign language learning/teaching in a formal setting.

Referring to other relevant literature, the difference between CLIL and LSP is also discussed (Coyle et al. 2010; Dalton-Puffer 2011). According to the author, while "CLIL clearly states that content-learning objectives are equally or even more important than language-learning objectives, $[\ldots]$ in LSP, which is language-led, language-learning objectives are of primary importance" (38). Nowadays, CLIL is implemented in state schools in the EU with the aim of improving existing deficiencies in the formal learning of foreign languages (FL) with no detrimental cost to content learning (Bruton 2013). The remaining sections of Chapter 1 


\section{Reviews}

stress the fact that the evolution of the field has resulted in new employment opportunities, as well as being helpful for the migration of different groups, which may include the less privileged, who require more supportive FL instruction.

Chapter 2 serves to illustrate the various competences claimed to be indispensable but not exclusive to ESP teachers:

Although ESP teaching tends to be specifically determined by concrete needs of target learners, $[\ldots]$ essential similarities can be observed between ESP and EGP instruction [since] both of them aim at meeting learners' needs and preparing them for communication with foreign language users in different contexts. (57)

Likewise, teaching methods are argued to be similar in most common approaches: the activity-oriented approach (action to be taken by the learners), the skilloriented approach (reading, writing, listening, speaking), the genre-oriented approach (discourse analysis), the task-oriented approach and the singlepractitioner approach. However, the emphasis on mastering discipline-specific knowledge can result in a clear improvement in ESP teachers' practice and, therefore, materials selection is an area of great concern. In this respect, collaboration between the ESP units and other departments may be part of the solution, as illustrated by many multi-disciplinary activities found in the countries that implement such a collaborative approach. In particular, the interactive nature of this approach can engage students in active processing of information resulting in greater retention of subject matter, as also claimed in McCafferty et al. (2006). In addition, designing and implementing successful ICT can also facilitate ESP instruction since it is the pivot on which the success of distance educational programs revolves today.

The focus on student needs is the main topic of Chapter 3. Hyland's (2006) main questions of what and how to teach in course development are specifically addressed, as well as his definition of the concept of needs:

Needs is actually an umbrella term that embraces many aspects, incorporating learners' goals and backgrounds, their language proficiencies, their reasons for taking the course, their teaching and learning preferences, and the situations they will need to communicate in. Needs can involve what learners know, don't know or want to know, and can be collected and analysed in a variety of ways. (73-74)

The historical research provided in this chapter also shows how the concept of student needs is catered for by many ESP approaches. Furthermore, language theories also determine how to deal with needs analysis (NA). For example, considering content-based teaching, researchers seem to adopt a scaffolding approach to both reading and writing instruction. As for obtaining information from students, there are different sources of information and techniques of data elicitation that are nowadays available in the ESP classroom. Although most NA 


\section{Reviews}

data is expected to be found in the use of questionnaires or interviews in most experimental methods, there are other less experimental contexts where data can be collected, from observation to documentation samples. Moreover, drawing on Swales's (1990) seminal work on genre analysis, Bhatia's (1993) research provides a practical methodological procedure for integrating text analysis with social context analysis. Finally, corpus analysis techniques in more recent studies are claimed to serve to identify a given language variety or type of text. Yet, irrespective of the research method employed, needs analysis is claimed to be a crucial stage of every ESP course. In a nutshell, teachers will find a series of measures that they should bear in mind in order to contribute to meeting student needs and better performance by paying attention to different styles of learning.

The remaining chapters of the book focus on ESP curriculum and syllabus development (Chapter 4), course materials and their evaluation (Chapter 5) with an emphasis on those assessment activities that best suit each course syllabus (Chapter 6). Although many ESP teachers do not seem to employ a single textbook, using one might help those instructors who have less experience.

Certainly, the guidelines provided in these chapters could facilitate not only novice teachers' practices but also help students who can get ahead with the textbook materials at home, more independently, and discover or make headway by themselves once they are finished with each textbook unit. However, tailoring instruction to meet individual needs is not discussed in detail since differentiation is assumed to be more commonly found with younger learners. In brief, university teachers eager to learn from flexible approaches to teaching English for specific purposes at university can find a broad range of suggested tasks.

As discussed in Chapter 6, facilitating group work is an excellent strategy for fostering participation in the ESP classroom. Furthermore, regular assessment and feedback allows teachers to adapt their teaching methods to their students' needs and learning conditions. For instructors, however, one might argue that it is not only crucial to select the textbook that best suits their students' educational background, but also the one which takes into account diversity end ethnicity. In addition, they need to consider the fact that in a general classroom, the study materials should also target students with learning difficulties. If we need to adapt the material to too many students, it would be better to search for supplementary resources. Students coming from abroad also need to be reevaluated and integrated into their new educational environment.

Furthermore, study materials should comply with the concept of authenticity. An ESL lesson is expected to exhibit language taken from real life. Quoting Freda Mishan, Lesiak-Bielawska bases the "authenticity centered" approach on "the use 


\section{Reviews}

of authentic texts for language learning and the preserving of this authenticity throughout the procedures in which they are implicated" (129-130). However, this does not mean that one needs to do without classical methodologies. Note that today many ESP practitioners have been able to tackle the concept of 'authenticity' in their classrooms, for example, using computer-assisted language learning (CALL) and other learning technologies to foster the students' literacy in traditional scientific disciplines.

On the other hand, concerns about public misinformation ranging from politics to science are growing nowadays and there is a need for more systematic analyses of science communication in new media environments. Hence, it is not all about authentic materials but also well-informed sources for the study materials used in the ESP classroom. Once ESP instructors have selected appropriate Internet resources, they can better adjust and design their syllabi because they can share their evaluations and compare them with other trainers all around the world.

In fact, Chapter 7 addresses the question of how to incorporate technology in today's ESP instruction: “Technology has not only expanded ESP teachers' ability to design new materials and share them with other Internet users, it has also given rise to new forms of multimodal discourse combining texts, podcasts, images or video" (173). The chapter strongly argues in favor of virtual environments "to recreate real-life situations" (174) and provides the reader with useful links with detailed instructions. In addition, online ESP courses in a distance or blended learning framework are also argued to be well-suited to ESP teaching. Some illustrative references of best practices are mentioned to illustrate several cases of successful online methodologies specially applied to different language training courses.

In sum, the book is highly recommended for teacher trainers and trainees since it provides useful information on the task of developing a creative classroom syllabus following clear guidelines, although teachers need to develop their own tailormade materials to meet their classroom targets (ESP, EAP, LSP). To demarcate effective and real teaching goals for their projects, it is suggested that instructors should thoroughly examine their teaching resources to address the specific expectations and contents relating to the subjects taught in English as a second or foreign language. By examining different approaches, they will also have a broader perspective concerning the teaching purposes of their classroom syllabus. Moreover, they will be aware of the opportunities that related methodologies offer for their students to prove their ability to express themselves in domestic and daily interaction, dealing with a wide variety of topics. Readers can also feel motivated to scrutinize inspiring academic books like the one reviewed here. 


\section{Reviews}

\section{Works Cited}

Bhatı, Vijay K. 1993. Analysing Genre: Language Use in Professional Settings. London: Longman.

Bruton, Anthony. 2013. "CLIL: Some of the Reasons Why ... and Why Not". System 41 (3): 587597.

CoYle, Do, Philip Hood and David MARSH. 2010. CLIL: Content and Language Integrated Learning. Cambridge: Cambridge U.P.

Dalton-Puffer, Christiane. 2011. “Content-andLanguage Integrated Learning: From Practice to Principles?" Annual Review of Applied Linguistics 31: 182-204.
HyLAND, Ken. 2006. English for Academic Purposes: An Advanced Resource Book. London: Routledge.

McCafferty, Steven G., George M. Jacobs and Ana Christina DaSilva IdDings. (eds.) 2006. Cooperative Learning and Second Language Teaching. Cambridge: Cambridge U.P.

NazArI, Mostafa. 2020. “Language for Specific Purposes Teacher Education: A Scoping Review". MEXTESOL Journal 44 (4): 1-13.

Swales, John M. 1990. Genre Analysis: English in Academic and Research Settings. Cambridge: Cambridge U.P. 